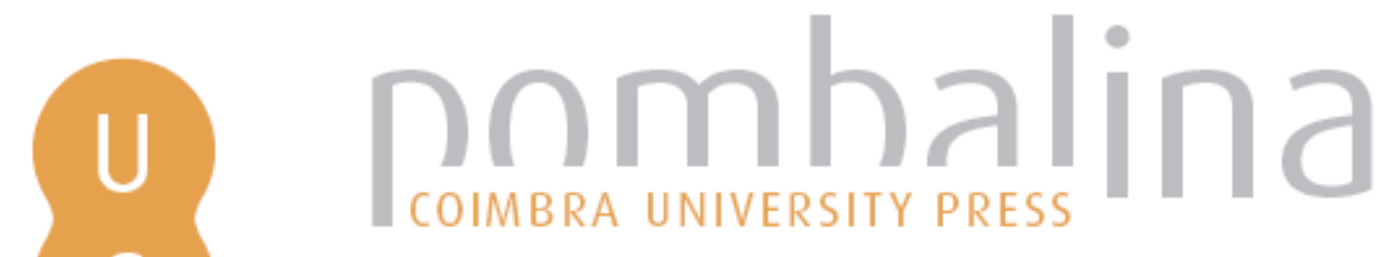

\title{
Um historiador "esquisito": a epanáfora amorosa de D. Francisco Manuel de Melo
}

Autor(es): $\quad$ Fraga, Maria do Céu

Publicado por: Imprensa da Universidade de Coimbra; Ediciones Universidad

URL

persistente: URI:http://hdl.handle.net/10316.2/31510

DOI: $\quad$ DOI:http://dx.doi.org/10.14195/978-989-26-0245-5_7

Accessed : $\quad$ 26-Apr-2023 12:24:19

A navegação consulta e descarregamento dos títulos inseridos nas Bibliotecas Digitais UC Digitalis, UC Pombalina e UC Impactum, pressupõem a aceitação plena e sem reservas dos Termos e Condições de Uso destas Bibliotecas Digitais, disponíveis em https://digitalis.uc.pt/pt-pt/termos.

Conforme exposto nos referidos Termos e Condições de Uso, o descarregamento de títulos de acesso restrito requer uma licença válida de autorização devendo o utilizador aceder ao(s) documento(s) a partir de um endereço de IP da instituição detentora da supramencionada licença.

Ao utilizador é apenas permitido o descarregamento para uso pessoal, pelo que o emprego do(s) título(s) descarregado(s) para outro fim, designadamente comercial, carece de autorização do respetivo autor ou editor da obra.

Na medida em que todas as obras da UC Digitalis se encontram protegidas pelo Código do Direito de Autor e Direitos Conexos e demais legislação aplicável, toda a cópia, parcial ou total, deste documento, nos casos em que é legalmente admitida, deverá conter ou fazer-se acompanhar por este aviso.

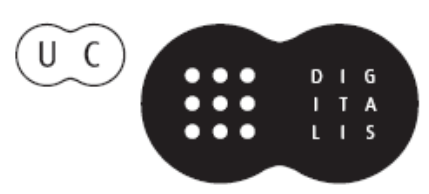


Marta Teixeira Anacleto

Sara Augusto

Zulmira Santos

Coordenação

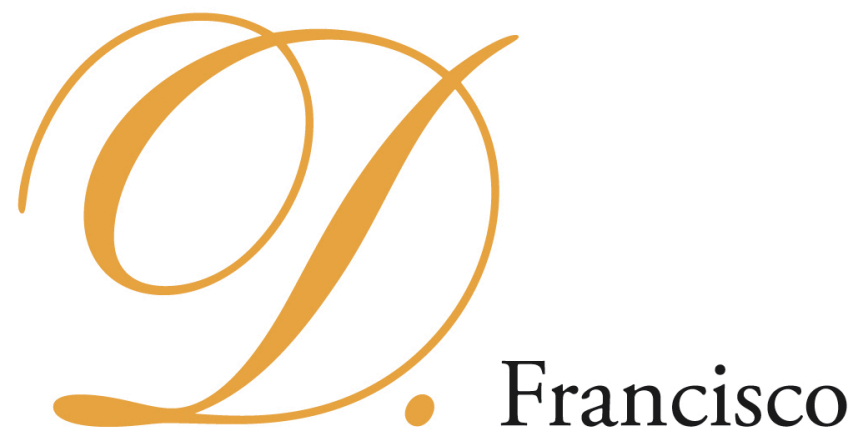

Manuel de Melo e o

Barroco Peninsular 


\title{
EDIĈ̣̃O
}

Imprensa da Universidade de Coimbra Ediciones Universidad Salamanca

\section{COORDENAÇÃo EDITORIAL}

Imprensa da Universidade de Coimbra

URL: http://www.uc.pt/imprensa_uc

Vendas online: http://www.livrariadaimprensa.com

\section{CONCEPÇÃO GRÁFICA}

António Barros

\section{REVISÃO TEXTO}

Sara Augusto

\author{
Pré-Impressão, Impressão e ACABamento \\ www.artipol.net
}

\section{IS B N}

978-989-26-0044-4 (Portugal)

978-84-7800-194-1 (Espanha)

DEPósito LEGAL

$311680 / 10$

OBRA PUBlicada COM O APOIO DE:

FCT Fundação para a Ciência e a Tecnologia

MINISTÉRIO DA CIÊNCIA, TECNOLOCIA E ENSINO SUPERIOR Portugal

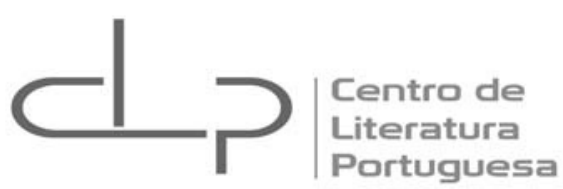

A presente publicação insere-se no Grupo "Poéticas" (coordenação de Marta Teixeira Anacleto) do Centro de Literatura Portuguesa, Unidade de I\&D financiada pela Fundação para a Ciência e a Tecnologia, ao abrigo do Programa Operacional Ciência e Inovação 2010.

(C) Agosto 2010

IMPRENSA DA UNIVERSIDADE DE COIMBRA

EDICIONES UNIVERSIDAD DE SALAMANCA 
Marta Teixeira Anacleto

Sara Augusto

Zulmira Santos

Coordenação

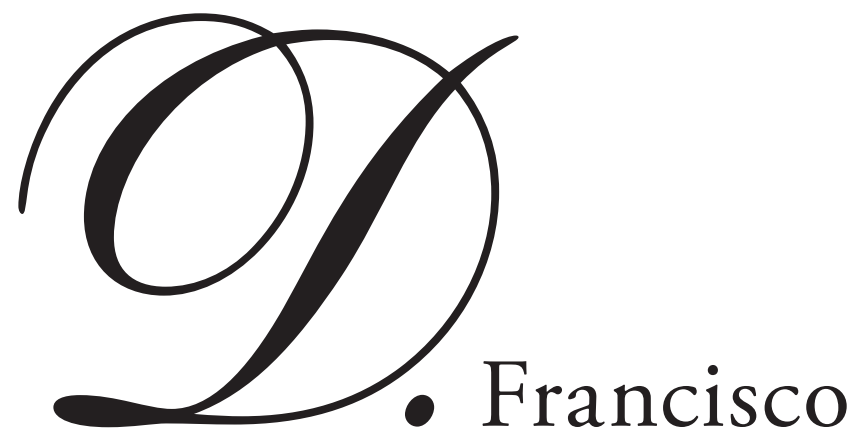

Manuel de Melo e o Barroco Peninsular

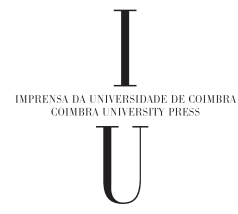


PARTE II

POÉtICAS DO BARROCO 


\section{Maria do Céu Fraga \\ Universidade dos Açores}

\section{UM HISTORIADOR «ESQUISITO»: A EPANÁFORA AMOROSA DE D. FRANCISCO MANUEL DE MELO}

Na obra de D. Francisco Manuel de Melo a Epanáfora Terceira amorosa, datada de 1654, representa um texto muito distinto dos outros - mesmo das restantes relaçôes com que foi agrupada num volume em 1660, sob o título Epanáforas de vária história portuguesa ${ }^{I}$. A diversidade, aliás, é a tónica do volume, mesmo se quase todas as narrativas se aproximam pelo seu carácter de contemporaneidade e se sente a unidade da perspectiva do autor, que viveu os episódios evocados e agora se preocupa em fazer o seu relato e análise: a Epanáfora Primeira, de natureza política, recai sobre as Alteraçôes de Évora de 1637, a Segunda, Trágica, sobre o naufrágio da Armada Portuguesa em França, em 1627. Já a Quarta, Bélica, se ocupa do conflito do canal de Inglaterra entre as Armadas Espanholas e Holandesas, em 1639, enquanto a Quinta, Triunfante, trata da Restauração de Pernambuco em 1654.

A Terceira, a Epanáfora Amorosa, de que agora nos ocupamos, é sobre o Descobrimento da Ilha da Madeira, em 1420.

Normalmente D. Francisco, através de alguns parágrafos que cumprem a função de dedicatória ou prólogo, declara as intençôes das suas obras. No caso da Epanáfora Terceira, dirige-se a um amigo para apresentar o seu texto como fruto da ocupação útil do tempo e anunciar a leveza do tema. Logo à partida, fala da dificuldade sentida em caracterizar a sua escrita, sabendo apenas que deseja «aliviar o ânimo, escrevendo algũa obra de mais divertimento que as passadas». As implicaçôes que teria a escolha de um caminho (de um género?) já trilhado não lhe agradam: «confesso-vos que me acho medroso para Coronista, rudo para Poeta, confuso para Filósofo, melancólico para Moral; mas para tudo menos que para me achar ocioso» ${ }^{2}$.

Relembremos alguns momentos da Epanáfora, vendo nela o fruto do desejo de aliar, numa narrativa leve, sucessos motivados pelo amor e a escrita, mais grave e retoricamente regrada, dos sucessos de valentia. Resumindo imperfeitamente, uma primeira parte conta

\footnotetext{
${ }^{1}$ Lisboa, na Officina de Henrique Valente de Oliueira, 1660. No presente trabalho, adoptámos a edição da Epanáfora Terceira feita por José Manuel de Castro (Descobrimento da Ilha da Madeira. Ano 1420. Epanáfora Amorosa. Lisboa: 1975), em livro que, além de ser profusamente anotado e indicar bibliografia útil, inclui também uma leitura da Relação de Francisco Alcoforado. Referir-nos-emos a ele simplesmente como Epanáfora Amorosa.

${ }^{2}$ Epanáfora Amorosa, pp. 31-32.
} 
como o inglês Roberto Machim se apaixona por Ana Arfet, e com o auxílio de companheiros fiéis foge com ela de Inglaterra, com a intenção de passar a França. A inexperiência do grupo e as correntes marítimas fazem-nos aportar à Madeira, onde permanecem até que Ana, já debilitada pela aventura e pelo remorso, morre. Roberto não resiste à dor, e morre também, dias depois. Os companheiros abandonam a ilha, movidos pela esperança de regressar à pátria. No entanto, passam da escravidão do mar à dos homens, e são feitos prisioneiros em Marrocos. Na prisão, surge o elo de ligação entre esta primeira narrativa e uma segunda: na masmorra encontrava-se Morales, piloto experiente, natural de Sevilha («homem prático na arte da navegação»)

Neste ponto, o autor faz um corte na sua narrativa, para passar a contar a saga marítima dos portugueses. Impóe-se a figura do Infante D. Henrique, o novo mapa do mundo que então se começa a desenhar, dando ocasião a que, d' «entre as pessoas» que acompanham o Infante se passe a dar relevo a João Gonçalves Zarco. E o relato continua até que, por promessa e testamento do mestre de Calatrava (1416, filho do rei D. Fernando de Aragão) se resgatam muitos cativos de Marrocos. Reencontramos então o piloto João de Morales, em 1420, na armada de Gonçalves Zarco e a partir desse momento acompanhamos as naus na sua viagem de descobrimento, acompanhamos as calmarias e hesitaçóes, ouvimos o discurso com que Zarco incita os marinheiros a prosseguirem a missão, e, vemo-los desembarcar na Madeira, reconhecendo Morales todos os vestígios da sua anterior estadia na ilha. Com eles regressamos, para assistirmos à recepção que a corte e o rei fazem a Gonçalves Zarco, sempre acompanhados pelos comentários laudatórios do autor, que declara a sua relação de parentesco com o navegador.

No Hospital das Letras, num excurso que se impóe pela autoridade de Justo Lípsio, D. Francisco distingue duas maneiras de escrever a História. Uma, inspirada por Tito Lívio, é "austera e incorrupta»: os factos e a cronologia impóem-se ao escritor que, de seu, poderá apenas dar o estilo. A segunda forma, pelo contrário, requer que o historiador «entreponha o seu estilo, quando refere as acçóes, e sobre elas levante discursos, como não sejam alheios ou prolixos». Os autores paradigmáticos desta forma de conceber a historiografia são Xenofonte e Tácito.

Esta segunda forma só será lícita a quem delimitar de tal forma a sua matéria que escreva sobre uma só acção. Ou, mais ainda, a quem se ocupar «da vida de um príncipe, o sucesso de uma guerra, a relação de movimentos e transferência de república, a estes tais afirmo ser lícito e obrigatório salpicar e sentenças, observaçóes e juízos a sua história, porém com tal siso e mesura que não seja o esmalte mais que o ouro, (sob) pena de degenerarem de historiadores a discursantes». A estes, é necessário que «o que faltou em riqueza à narração, supra a erudição em nosso [do leitor] proveito»"

\footnotetext{
${ }^{3}$ José Manuel de Castro traça uma perspectiva sumária e clara de «A lenda e a história na Epanáfora Amorosa» no livro indicado na n. 1, pp. 99-109, referindo bibliografia importante que nos dispensamos de apontar aqui. Também Edgar Prestage dedica as páginas 297 a 300 do seu indispensável D. Francisco Manuel de Mello. Esboço biographico (Lisboa, Fenda, 1996, edição fac-similada da edição de 1914) à análise das supostas intençôes políticas que teriam levado D. Francisco Manuel de Melo a compor esta Epanáfora. Mais recente, distingue-se o estudo de João David Pinto Correia, «Da História à Literatura. Ainda o Descobrimento da Madeira» (Actas do III Colóquio Internacional de História da Madeira. Funchal: CEHA, 1993, pp. 201-06.

${ }^{4} \mathrm{Na}$ edição de Jean Colmes, Le dialogue Hospital das Letras de D. Francisco Manuel de Melo. Paris: Fundação Calouste Gulbenkian - Centro Cultural Português, 1970, pp. 136 e ss. Cit. pp. 136 e 137.
} 
A observação é tanto mais importante quanto é certo que, ao tomar para ocupação da sua pena o descobrimento da Ilha da Madeira, D. Francisco tomava um assunto que já fora tratado, tanto no campo da literatura como da historiografia.

E se não conhecia talvez os relatos de António Galvão e de Gaspar Frutuoso, inéditos na época, mas circulando manuscritos, D. Francisco Manuel tem nas mãos, e invoca em seu favor, a Relação manuscrita de Francisco Alcoforado, escudeiro do Infante D. Henrique $^{5}$. Não esquece nem a narrativa do descobrimento escrita em latim pelo Pregador Padre Manuel Clemente, nem a Década I de João de Barros e conhece as rimas da Insulana, de Manuel Tomás (1635), a quem se refere elogiosamente no Hospital das Letras ${ }^{6}$.

Com o testemunho do escudeiro do Infante procura «inculcar ao Mundo como verdadeira ũa história tão esquisita», uma história que, diga-se, qualquer um dos outros escritores tomara como pertencendo ao domínio da lenda e que, certamente, não consideraria factualmente verídica, mesmo se lhe atribuísse o fundamento de verdade histórica que em geral se concede à tradição.

Novo, sim, é o propósito de desenvolver a história deixando-se contaminar pelos processos mais comuns da literatura e, nomeadamente, da novela, no desenho das personagens e acontecimentos, e também na construção discursiva. Mas, tendo em conta que D. Francisco Manuel de Melo tem presente a noção de utilidade política dos seus escritos, e que a partir da verdade, memória e eloquência, «escreve sobre a realidade, não descreve a realidade» ${ }^{7}$, facilmente se compreenderá que hibridismo serve aos seus propósitos, como, aliás, serve ao seu próprio ânimo de escritor, pouco propenso a aceitar cegamente os preceitos estabelecidos para cada género ${ }^{8}$. Os prólogos de muitas das suas obras o declaram, um pouco à maneira do que diziam os escritores de novelas pastoris ou como o Padre António Vieira no prólogo do $1^{\circ}$ volume dos Sermoens: a variedade afasta o fastio da semelhança.

Como o próprio D. Francisco comenta, a recepção a El mayor pequeño, a sua biografia de S. Francisco de Assis, confirmava essa sua inclinação para o hibridismo: acusaram-no de ser "confuso para historiador e de afectado para moral», enquanto que a obra "para livro de oração, compreendia sobeja cultura, e, para relação, repreensível brevidade»"

Náo admira assim que eleja como modo de escrever a história o de Tácito, e adopte, ao menos explicitamente, o Cardeal Guido Bentivoglio (1579-1644) como émulo, rasgando elogios à sua obra, mas sentindo que, ao tomar como tema a lenda do Machim e os feitos de amor, tem condiçóes para vencer o modelo, "posto que sábio, velho e religioso». Polígrafo, o

\footnotetext{
${ }^{5}$ Sobre uma possível identificaçáo do manuscrito, veja-se Jean Fontvieille, «A lenda de Machim» in Congresso Internacional de História dos Descobrimentos. Actas, vol. III. Lisboa: Comissão Executiva das Comemorações do V Centenário da Morte do Infante D. Henrique, 1961, pp. 197-237.

${ }^{6}$ Nos dez livros da Insulana, a história de Ana Arfet e Roberto Machim, «descobridores», ocupa o segundo, sendo narrada pelo piloto castelhano (aí, João dos Amores) a Zarco, durante a viagem.

${ }^{7}$ Maria Tereza Amado, "A historiografia barroca peninsular», in I Congresso Internacional do Barroco. Actas. Porto: Reitoria da Universidade do Porto - Governo Civil do Porto, 1991, vol. I, pp. 103-11.

${ }^{8}$ A título de exemplo, vejam-se os comentários tecidos no Hospital das Letras a propósito da arbitrariedade da autoridade dos modelos épicos consagrados, e às contradiçôes que entre eles se encontram (cf. também Giacinto Manuppella, «Uma sinfonia crítica imperfeita: o Hospital das Letras de D. Francisco Manuel de Melo», in As Grandes Polémicas Portuguesas. Lisboa: Verbo, 1964, vol. I, pp. 238 ss).

${ }^{9}$ Estas palavras de Lípsio, que merecerão a anuência do Autor, encontram-se no Hospital das Letras, ed. cit, p. 96.
} 
cardeal deve a sua fama de historiador sobretudo às Relazioni que escreveu no tempo da sua nunciatura na Flandres e em França ${ }^{10}$. Entre sucessos e ambientes muito diversos daqueles que surgem nas Epanáforas, também na Relação Della fuga di Francia o amor apaixonado se mostra funesto, apresentando-se a história à reflexão do leitor, que é continuamente interpelado e guiado pelo escritor.

A Epanáfora Amorosa conta, pois, duas histórias. A possível unidade entre elas resulta mais da intenção didáctica e moralizadora que as percorre do que propriamente do entrecho ou de processos narrativos de composição. Nesse aspecto, a Epanáfora recorre aos artifícios mais comuns na novela da época, que, numa estrutura mais ou menos elaborada, faziam desenrolar várias narrativas paralelas, levando-as a interceptarem-se aqui e além, através da presença de personagens ou acontecimentos pertencentes a mais do que um plano narrativo.

A primeira destas histórias é uma história de amor, centrada na figura de Roberto Machim. A segunda narra um acontecimento histórico, enaltecendo a acção e qualidades do Infante D. Henrique e, sobretudo, de Gonçalves Zarco. A primeira, ditada pelo Amor, tem um fim trágico; a segunda, pelo contrário, mostra a recompensa da virtude.

Em grande medida, é o contraste entre ambas, o choque entre o castigo e a recompensa, entre a imprudência e o heroísmo esclarecido, que propicia a mensagem, impedindo que a tónica final da Epanáfora seja a melancolia ( $A$ melancolia, ainda que seja negra, não dá boa tinta ao que escreve», ajuíza numa carta a um familiar, numa observação que, dirigindo-se em primeiro lugar à inspiração poética, se pode também alargar ao à escrita de cunho moralizante ${ }^{11}$ )

Como desenhar a figura de Roberto de forma a que ele possa também ser, a seu modo, um herói? Como interessar o seu leitor? Em primeiro lugar, construindo Roberto como personagem literária, afastando-o temporalmente da sua época e recriando ideais da própria época de D. Francisco, misturando de uma forma pouco explicita os métodos da historiografia e os da criação literária. O historiador E. H. Carr, numa conferência proferida na Universidade de Cambridge, falava na "compreensão imaginativa»: um historiador pertence à sua época, está-lhe submetido pelas próprias condiçóes da vida humana. Exigese-lhe a descentração, exige-se, sob pena de, à moda romântica, a interpretação valer mais do que os factos, que ele seja capaz de recuar no tempo e de se situar na mentalidade e na vida do tempo que estuda ${ }^{12}$.

Mas D. Francisco tem em vista menos a reconstituição de um episódio do que a lição que dele pode extrair para os seus contemporâneos, e, em particular, para os cortesãos do seu tempo. Levantam-se-lhe, portanto, preocupaçóes de duas ordens. Tem de cativar o seu leitor, e ao mesmo tempo, deleitando-o, levá-lo a exercitar-se na procura da verdade. Ou seja, as personagens e as acçóes têm de oferecer vários níveis de análise, e através da análise da sua acção circunstancial deverá atingir-se um nível mais universal, que dá, ele sim, sentido ao grande teatro do mundo.

\footnotetext{
${ }^{10}$ D. Francisco refere-se-lhe no Hospital das Letras, ed. cit., p. 95.

${ }^{11}$ Cartas Familiares, pref. e notas de Maria da Conceição Morais Sarmento. Lisboa: Imprensa Nacional-Casa da Moeda, 1981, p. 122. O destinatário desta carta, datada da Torre, 9 de Junho de 1646, seria, já na opinião de Prestage, D. Francisco de Melo.

${ }^{12}$ Edward H. Carr, A História. Lisboa: Gradiva, 1986, p. 21.
} 
Roberto agirá «como homem discreto» (a expressão ocorre na p. 36, ligada à paciência ao fingimento prudente - com que o apaixonado Roberto forja os seus planos de fuga), mas esta característica, tão própria da época de $\mathrm{D}$. Francisco resistirá pouco tempo à paixão.

Desde o início, a personagem é apresentada como sendo um jovem nobre, de segunda ordem, é certo, mas que se destaca entre os mais e se aplica em "pensamentos mais altos». Resume o narrador: «Ânimo forte, juízo excelente, idade gentil, fortuna próspera, eram seus íntimos conselheiros: ajudando-se das partes pessoais, que em Roberto (não acaso) fizeram concurso» ${ }^{13}$.

Captada (q. b.) a simpatia do leitor, o autor preocupa-se em fazer falar Roberto. Nos momentos fulcrais da acção, Roberto mostrará, como qualquer herói de uma obra historiográfica da época, o seu talento oratório. Mas como se verá, nem sempre esse talento corresponderá à elevação moral e ao equilíbrio. No entanto, o ímpeto dos seus discursos será eficaz, no sentido em que conseguirá demover e levar à acção os companheiros, persuadindoos de que a fuga com Ana constitui a vingança justa de um amor maltratado e ofendido pelos planos de casar a jovem com um nobre eleito pelos pais.

Ana, por seu turno, vê louvadas as suas qualidades pelo narrador com certo laconismo. Fica a saber-se que é social e economicamente superior a Roberto, o que não é, dentro da perspectiva adoptada pelo narrador, um pormenor displicendo. É uma «donzela fermosíssima», detentora de uma desusada harmonia entre os dotes de corpo e espírito.

Mas apesar do cunho literário do entrecho e, por conseguinte, da fantasia que se poderia esperar, cedo se faz ouvir o moralista da Carta de Guia de Casados. Nas novelas da época, a análise sentimental contemplava habitualmente quer a perspectiva masculina, quer a feminina, e assim na novela pastoril, por exemplo, com uma verosimilhança dada apenas pelas convençóes do género, os escritores faziam ouvir a voz das pastoras que revelavam, com fina subtileza analítica, os seus estados sentimentais. Aqui, na Epanáfora Amorosa, é ao narrador que caberá fazer consideraçóes sobre a essência dos sentimentos ou sobre o desenvolvimento da acção. E, diga-se, apesar de alguns excursos poderem parecer à sensibilidade dos nossos dias excessivamente empolados, a beleza formal e a conceptualização de outros torna-os atractivos ainda hoje. Como náo lembrar as palavras de Prestage, quando, ao sancionar o trecho dedicado à análise da saudade, o inclui entre as razóes por que esta relação "não é para desprezar» ${ }^{14}$ ?

De Ana, o narrador pouco dirá, rematando o seu elogio com a seguinte avaliação: «era esmalte de suas perfeiçôes, seu recato».

Apresentadas as personagens, passará o autor a mostrar o verdadeiro agente: o Amor. Enganando as personagens, é ele quem lhes faz crer que merecem recompensa e que por momentos desculpabiliza o seu procedimento, matizando com traços de bravura os planos de fuga e a viagem até à Madeira.

${ }^{13}$ Epanáfora Amorosa, p. 35.

${ }^{14}$ Veja-se a "Introdução» que escreve para a sua edição das Epanáforas (3a ed. Coimbra: Imprensa da Universidade, 1931), p. VII. A passagem, que se encontra nas pp- 42 e ss. da Epanáfora, é uma das mais clássicas definiçóes da saudade, e encanta Prestage a ponto de ele a transcrever parcialmente no seu estudo sobre $D$. Francisco Manuel de Melo (pp. 277-278). 
Compreendida nas intençôes que animam o autor, a morte de Ana seria inevitável. E de certa maneira, só quando é vencida pela «senhora dos mortais» que é a Morte, Ana ganha verdadeira dimensão na narrativa. Os sentimentos de Roberto, que até esse momento eram contidos, e velada ou indirectamente expressos, soltam-se num discurso longo em que, como notou já José Manuel de Castro, se acumulam os elementos mais típicos do monólogo dramático e que poderia ter lugar, pelo encaminhamento e características retóricas, numa cena de tragédia ${ }^{15}$.

É, pois, a uma personagem sem vida que Roberto dirige o seu discurso. A hesitação em que a análise se depara com sentimentos muito contraditórios e incompreendidos, conduz da culpa pessoal à nobilitaçáo de uma luta interior escalpelizada em imagens muito do agrado do autor e da época. "Errei? Ou atrevi-me?», pergunta-se Roberto, para concluir afastando qualquer responsabilidade humana na morte de Ana: «As flores mais mimosas da Primavera são as que primeiro se acabam» (p. 51).

O excesso, a desmesura da paixão eram evidentes demais. D. Francisco sente necessidade de pôr na boca de um companheiro de Roberto, «mais anciáo que os outros e mais experimentado nos sucessos do amor e do tempo» o discurso que leve à moderação e à aceitação das "tragédias de um mundo sempre trágico». O pessimismo moralizador de D. Francisco expressa-se. O discurso que contrapóe ao de Roberto faz lembrar a um tempo o coro da tragédia clássica, e os tópicos da pregação seiscentista, tão influenciada por Séneca.

A morte de Ana surge então como exemplar, como a morte dos condenados no Sermão ao enterro dos Ossos dos Enforcados pregado pelo Padre António Vieira: «a crueldade que se executa (se se executa) nos delinquentes é misericórdia». Mais do que espelho de fraqueza, Ana converte-se no exemplo a evitar e em aviso. A sua morte, como a de Roberto, aliás, responde ao "quare?» que tão presente esteve na consideração barroca do mundo. E que eles são exemplo a observar e a meditar, fica bem claro no próprio vocabulário empregue: teatro e espectáculo são palavras presentes na narrativa.

Os «sucessos de Amor» contados por D. Francisco não podiam ter um desfecho feliz. Gracián, responsável máximo pela noção de cortesia que enforma a obra de D. Francisco Manuel, lembrou que a paixão tem regras, e que a fundamentar o amor deve estar, num primeiro passo, a racionalização da paixão. $\mathrm{O}$ amante deve perceber o seu estado, e deve poder ter julgamento sobre a sua vontade. Ora Roberto não se acautelou, e se aos seus olhos parecia pertencer-lhe a condução da acção, a verdade é que, mesmo quando arquitecta os pormenores da fuga com Ana, não é senhor dos seus pensamentos.

A ilha da Madeira surge nesta narrativa como locus amenus e conclusus, oferecendo abrigo aos fugitivos ingleses. A descrição, literariamente bem conseguida, que dela se nos apresenta encerra os elementos mais característicos do desenvolvimento habitual dos tópicos, sendo que também «nenhum rasto de que fosse habitada se descobria» e cada nova observação, como «a imensa quantidade e simpleza dos pássaros[,] causava nova admiração nos homens e, nos pássaros, nenhum espanto sua companhia» ${ }^{16}$.

\footnotetext{
${ }^{15}$ Cf. op. cit., pp. 24-25.

${ }^{16}$ Epanáfora Amorosa, p. 45.
} 
Não se desenha, no entanto, a imagem do espaço idílico habitado pelo bom selvagem. Mesmo se o amor parece justificar os homens e mesmo se o narrador tem por vezes de refrear a sua compaixáo, a queda e a sombra do pecado estáo presentes na dissonância que se sente existir entre os enamorados, a razáo natural e a lei divina. A lei humana tem a sua razão de ser na conformidade entre a divina e a natural; Roberto e Ana quebraram tanto a lei humana como a divina. Náo se chega a apagar a noção de pecado, nem com o gesto do casal que, enquanto os companheiros procuram armar abrigos para se protegerem contra a possível inclemência de um clima desconhecido, «com singular devação» levantou um altar para o crucifixo que Ana trouxera consigo, e que vem mostrar que, apesar de tudo, tem esperança no perdão divino.

$\mathrm{O}$ contraste entre as atitudes e os valores que animam as personagens da primeira e da segunda parte da Epanáfora é evidente. Na primeira, o ancião que discursou pedia e desejava esquecimento para o casal inglês: "As vozes que até aqui foram de escândalo, ou não passaráo adiante, ou, se passarem, tu as verás trocadas de escândalo em piedade» (p. 53). Pelo contrário, para Gonçalo Zarco, herói da segunda narrativa, como para o Infante D. Henrique, a fama torna-se recompensa. Os seus ecos representam a consagração dos feitos, da obediência a um plano que transcende a vontade humana, como explica Zarco em discurso ao rei D. João: «O Infante como dedo índex da mão do Altíssimo, está apontando às veredas do universo (às naçóes mais incógnitas) por donde vossos vassalos caminham a conduzi-lo a vossa obediência» ${ }^{17}$.

A figura central deste segundo núcleo narrativo é João Gonçalves Zarco. Por isso, as páginas finais falam não só das viagens subsequentes ao descobrimento e do povoamento da Madeira, mas também da biografia e linhagem do navegador. Nesse passo, D. Francisco mostra com orgulho o parentesco que o liga a Zarco.

O tom agora não é lírico. Os excursos do narrador sublinham o heroísmo das personagens, e no longo discurso com que Gonçalves Zarco se dirige ao rei, a presença camoniana sugere a conotação épica da situação:

Contar-vos, senhor poderosíssimo, os trabalhos que passámos nesta peregrinação proluxa, ainda que breve, por mares nunca vistos e terras nunca descobertas, fora em algum modo prezar os serviços que nela vos fizemos. (p. 95)

As virtudes de Gonçalves Zarco são as mesmas que definem no tratado Politica militar en avisos generales o herói militar, numa época em que o valor guerreiro já não podia, por si só, definir o valor do cortesão. «Lo valor, la ventura, la ciência, la constância, la experiencia, la liberalidad, la limpieza, la humanidade, la ejeccución, la salud» - recorro à enumeração tal como ela é apresentada por Paulo Silva Pereira, que sublinha muito justamente serem as principais características aqui apresentadas relativas ao carácter moral, à disposição de ânimo $^{18}$.

\footnotetext{
${ }^{17}$ Epanáfora Amorosa, p. 75.

${ }^{18}$ Cf. a dissertaçáo de doutoramento de Paulo Silva Pereira, D. Francisco Manuel de Melo e o modelo do 'cortesáo prudente e discreto' na cultura barroca peninsular, apresentada à Faculdade de Letras da Universidade de Coimbra, 2007 (texto policopiado), pp. 320 e ss.
} 
Porque nele reconhecem a prudência que manifestamente não poderiam descortinar em Roberto, os marinheiros encontram alento no discurso que lhes dirige quando as calmarias os desanimavam. É, pois, por acção directa de Zarco que o empreendimento conhece um bom fim.

«Conquistaram os gregos, aos Persas, os romanos, aos Gregos; porém os Portugueses, em vez de estados, conquistaram elementos». João Gonçalves Zarco é um herói para o qual não havia modelo, mas que, mediante comentários orientados do autor, se vai integrando no desenho típico do cortesão prudente e discreto. Daí nasce também o interesse da cena em que é recebido pelo rei e do seu discurso, marcando a integraçáo do herói na corte, e dando ao narrador a possibilidade de acentuar como o favor do rei recompensa os bons serviços prestados por quem lhe obedece e nele confia. Ou seja, o narrador alia especularmente a fidelidade do cortesão e a grandeza do seu príncipe, à moda dos tratados, tâo correntes na época, que fornecem «avisos» para a vida áulica.

$\mathrm{Na}$ viagem do descobrimento oficial, Morales reconhece cada local da ilha. Reencontram-se as sepulturas de Roberto e Ana, o altar e o crucifixo. Nas últimas páginas, João Gonçalves dá sepultura aos «desditosos amantes», ordenando a construção da igreja de Cristo Salvador. No entanto, mesmo se o narrador faz alguma observação, não se detém nela: a clave não é agora lírica, é heróica. Os elementos do passado constituem apenas uma ponte de coesão entre as duas narrativas, e esta segunda parte integra-se nos quadrantes mais habituais nas outras Epanáforas de D. Francisco. O ponto original da Epanáfora Amorosa encontra-se na conjugação da duas narrativas e na constituição novelesca da primeira.

Também por isso, pela liberdade que dá de efabulação literária, esta Epanáfora que não se cinge à narrativa de factos testemunhados permite a expressáo mais inequívoca de muitas das características que norteiam D. Francisco, e que levam um historiador como Joel Serrão a considerá-lo exemplo perfeito da ambiência cultural e mental do seiscentismo português ${ }^{19}$.

Num poema muito conhecido ${ }^{20}$, D. Francisco interpela o Mundo: «Quem enganas, ó Mundo, em teu teatro?», para concluir que o discreto não será ludibriado pelas aparências. No mesmo sentido, através da Epanáfora Terceira, apoiado na sua experiência e na autoridade que a própria vida lhe dá, tenta conduzir o leitor no longo caminho da cortesania. Para o fazer, numa época em que se discutia a utilidade dos livros de entretenimento, e se continuava a aceitar que a loucura de D. Quixote era devida às suas leituras, D. Francisco urde um episódio novelesco e integra-o num relato coeso, em que tomam lugar Vénus e Marte. Não se trata apenas do reconhecimento do valor literário da crónica histórica; é também a afirmação do valor universalizante da História.

${ }^{19}$ Cf. Joel Serrão, «Aproximação da mentalidade de D. Francisco Manuel de Melo», in Colóquio /Letras, 33 (1976), pp. 51-61. Este estudo veio depois a ser integrado na "Introdução» à sua edição das Epanáforas. Lisboa: Imprensa Nacional-Casa da Moeda, 1997. Na primeira parte deste prefácio, Joel Serrâo sublinha o carácter totalizante que a História, compreendida como liçáo para a posterioridade, assume no universo cultural de D. Francisco, ao mesmo tempo que salienta a harmonia conseguida na sua obra entre o historiador, o político, o poeta e o retórico.

${ }^{20}$ É o soneto XI de A Tuba de Caliope, «Dez figas para vós, pois com furtado» (Obras Métricas. Ed. coordenada por Maria Lucília Gonçalves Pires e José Adriano de Freitas Carvalho. Braga: Ediçôes APPACDM de Braga, 2006, vol. II, p. 452). 
Da sua formação jesuíta, entre muitos outros aspectos, vem agora a sobressair a ideia de que nada no mundo surge por acaso, e que a mão da Providência se estende, compassiva e justa, no mundo dos homens. Por isso, se dá à literatura uma função lúdica, não esquece a influência que pode desempenhar na constituição do presente.

A quem a saiba ler, a história apresenta casos tão significativos como a literatura, quando se considera a universalidade que podem ganhar - e essa é, em última análise, a justificação para que as fronteiras entre a relaçáo histórica e a efabulaçáo literária se possam esbater na pena de um historiador «esquisito» que tenha a erudição e a agudeza necessárias para compreender e interpretar o mundo e o homem. 
Série

Documentos

Imprensa da Universidade de Coimbra

Coimbra University Press

2010

- U

C • 